\title{
PEMETAAN STATUS HARA $P$, pH dan C organik TANAH SAWAH DI DESA HILIBADALU KECAMATAN SOGAEADU KABUPATEN NIAS
}

\author{
Mapping Nutrient Status of Phosphate, Soil pH and Organic Carbon of Paddy Fields \\ In Hilibadalu Village Sogaeadu District Nias Regency
}

Charlan B Lombu*, Abdul Rauf, Supriadi

Program Studi Agroekoteknolgi, Fakultas Pertanian USU, Medan 20155

*corresponding author: Email: charlan.lombu2@gmail.com

\begin{abstract}
The purpose of this research is to survey and mapping nutrient status of total phosphate, available phosphate, soil $\mathrm{pH}$ and organic carbon at paddy fields Hilibadalu Village Sogaeadu District Nias Regency and its influence on rice production. Soil samples was analyzed at the Analytical Laboratory of PT Socfindo Indonesia North Sumatera Province. Which began in October to December 2016. The method used is Free Grid Survey semidetailed level survey and analysis of nutrient data total phospate by Acid destruction method $\left(\mathrm{HClO}_{4}\right)$, available phosphate by Bray II method, soil $\mathrm{pH}$ by $\mathrm{H}_{2} \mathrm{O}$ extraction and organic carbon by walkley \& black method and then interpret to the map nutrient status. The result of research showing that status total phosphate classified by 3 status such as, medium (81,59 ha), high $(81,15 \mathrm{ha})$ and very high $(27,26 \mathrm{ha})$. Available phosphate classified in 3 nutrient status such as very low $(39,11$ ha), low $(137,40$ ha) and medium (13,49 ha). Soil pH classified in 2 status such as moderately acidic (30,16 ha) and strongly acidic (159,84 ha). Organic carbon classified by 3 nutrient status such as very low (3,06 ha), low (135,84 ha) and medium (51,10 ha). Available phosphate and organik carbon affect rice production in Hilibadalu Village Sogaeadu District Nias Regency.
\end{abstract}

Keywords : Mapping Nutrient Status, Paddy Fields, Soil Survey

\begin{abstract}
ABSTRAK
Penelitian ini bertujuan melakukan survei dan pemetaan sebaran status hara P total, P-tersedia dan C-organik tanah sawah di Desa Hilibadalu Kecamatan Sogaeadu Kabupaten Nias dan pengaruhnya terhadap produksi padi. Analisis tanah dilakukan di Laboratorium Analitik PT Socfindo Provinsi Sumatera Utara. Yang dimulai pada bulan Oktober hingga Desember 2016. Metode yang digunakan adalah Survei Grid Bebas tingkat survei semidetail dan analisis data hara $\mathrm{P}$ total metode Destruksi Asam $\left(\mathrm{HClO}_{4}\right)$, $\mathrm{P}$ tersedia metode Bray II, $\mathrm{pH}$ tanah metode ekstrak $\mathrm{H}_{2} \mathrm{O}$ dan $\mathrm{C}$ organik metode Walkley \& Black serta menginterpretasikan dalam peta status hara. Hasil penelitian menunjukkan bahwa P total digolongkan dalam 3 status hara, yakni sedang $(81,59$ ha), tinggi $(81,15$ ha) dan sangat tinggi (27,26 ha). P tersedia digolongkan dalam 3 status hara, yakni sangat rendah $(39,11$ ha), rendah (137,40 ha) dan sedang (13,49 ha). $\mathrm{pH}$ tanah digolongkan dalam 2 status, yakni agak masam (30,16 ha) dan masam (159,84 ha). C organik digolongkan dalam 3 status hara, yakni sangat rendah (3,06 ha), rendah (135,84 ha) dan sedang (51,10 ha). P tersedia dan $\mathrm{C}$ organik mempengaruhi produksi padi di lahan sawah Desa Hilibadalu Kecamatan Gido Kabupaten Nias.
\end{abstract}

Kata kunci: Pemetaan Status Hara, Tanah Sawah, Survei Tanah

\section{PENDAHULUAN}

Survei tanah adalah mendeskripsikan karakteristik tanah-tanah di suatu daerah, mengklasifikasikannya menurut sistem klasifikasi baku, memplot jenis dan ketersediaan hara tanah pada peta dan membuat prediksi tentang sifat tanah. Informasi yang dikumpulkan dalam survei tanah membantu pengembangan rencana 
penggunaan lahan dan sekaligus mengevaluasi dan memprediksi pengaruh penggunaan lahan terhadap lingkungan (Rayes, 2007).

Menurut Hardjowigeno dan Rayes (2005), tanah sawah adalah tanah yang digunakan untuk bertanam padi sawah, baik terus menerus sepanjang tahun maupun bergiliran dengan tanaman palawija.

Produktivitas tanaman padi di Hilibadalu hingga saat ini 4,1 ton/ha (BPS, 2016) dan jauh dibawah standar nasional. Rendahnya produksi kemungkinan dapat disebabkan oleh beberapa faktor, seperti kandungan fosfor tersedia dan kadar bahan organik tanah yang terdapat pada tanah sawah. Sebagian petani dalam pengolahan lahannya masih belum menggunakan pupuk kimia untuk sumber phosphat. Juga sebagian petani di desa ini memiliki kebiasaan membakar jerami sisa panen setelah masa panen dilakukan, padahal kebiasaan tersebut berdampak buruk terhadap ketersediaan bahan organik di lahan sawah.

Berdasarkan landasan diatas peneliti melakukan penelitian untuk mengetahui penyebaran $\mathrm{P}$ total, $\mathrm{P}$ tersedia, $\mathrm{pH}$ tanah dan $\mathrm{C}$ organik di lahan sawah di Desa Hilibadalu sehingga dapat dilakukan pengolahan lebih lanjut.

\section{METODE PENELITIAN}

Penelitian ini dilaksanakan di lahan sawah Desa Hilibadalu Kecamatan Sogaeadu
Kabupaten Nias dengan luas 190 ha dan ketinggian tempat $\pm 18 \mathrm{~m}$ di atas permukaan laut. Sampel tanah yang telah diambil dianalisis di Laboratorium Analitik PT Socfindo Provinsi Sumatera Utara. Penelitian ini dilaksanakan dari bulan Oktober sampai Desember 2016.

Metode yang digunakan dalam penelitian ini adalah metode Survey Grid Bebas tingkat survei semi detail (kerapatan pengamatan 1 sampel tiap 12,25 hektar). Pengambilan sampel tanah di lapangan menggunakan cangkul pada kedalaman 0-20 cm. Sampel tanah diambil dari beberapa titik secara zig zag lalu dikompositkan kemudian dijadikan satu sampel. Dari tiap pengambilan contoh tanah tersebut, maka dicatat hasil pembacaan koordinat pada GPS.

Parameter yang diamati meliputi $\mathrm{P}$ total (metode destruksi asam $\left(\mathrm{HClO}_{4}\right)$ ), $\mathrm{P}$ tersedia (metode Bray II), pH tanah (metode ekstraksi $\mathrm{H}_{2} \mathrm{O}$ ) serta $\mathrm{C}$ organik tanah (metode Walkley and Black \%). Data yang diperoleh dianalisis dengan menggunakan analisis spasial menggunakan GIS (Geografic information system).

Output analisis spasial adalah kriteria $\mathrm{P}$ total, $\mathrm{P}$ tersedia, $\mathrm{pH}$ tanah dan $\mathrm{C}$ organik kemudian data tersebut dipetakan. Data yang diperoleh dikelompokkan berdasarkan kriteria penilaian sifat - sifat tanah yang dibuat oleh Staf Pusat Penelitian Tanah (1983) dan BPP Medan (1982).

Tabel1. Kriteria P Total, P Tersedia (Bray II) dan C organik

\begin{tabular}{lcccccc}
\hline \multicolumn{1}{c}{ Sifat Tanah } & Satuan & $\begin{array}{c}\text { Sangat } \\
\text { rendah }\end{array}$ & Rendah & Sedang & Tinggi & $\begin{array}{c}\text { Sangat } \\
\text { Tinggi }\end{array}$ \\
\hline P Total & $\%$ & $<0,03$ & $0,03-0,06$ & $0,06-0,079$ & $0,08-0,10$ & $>0,10$ \\
P Tersedia Bray II & ppm & $<8,0$ & $8,0-15$ & $16-25$ & $26-35$ & $>35$ \\
C Organik & $\%$ & $<1,00$ & $1,00-2,00$ & $2,01-3,00$ & $3,01-5,00$ & $>5,00$ \\
\hline
\end{tabular}

Tabel 2. Kriteria $\mathrm{pH}$ tanah

\begin{tabular}{lcccccc}
\hline Kriteria & $\begin{array}{c}\text { Sangat } \\
\text { masam }\end{array}$ & Masam & $\begin{array}{c}\text { Agak } \\
\text { masam }\end{array}$ & Netral & $\begin{array}{c}\text { Agak } \\
\text { alkalis }\end{array}$ & Alkalis \\
\hline $\mathrm{pH}\left(\mathrm{H}_{2} \mathrm{O}\right)$ & $<4,5$ & $4,5-5,5$ & $5,6-6,5$ & $6,6-7,5$ & $7,6-8,5$ & $>8,5$ \\
\hline
\end{tabular}




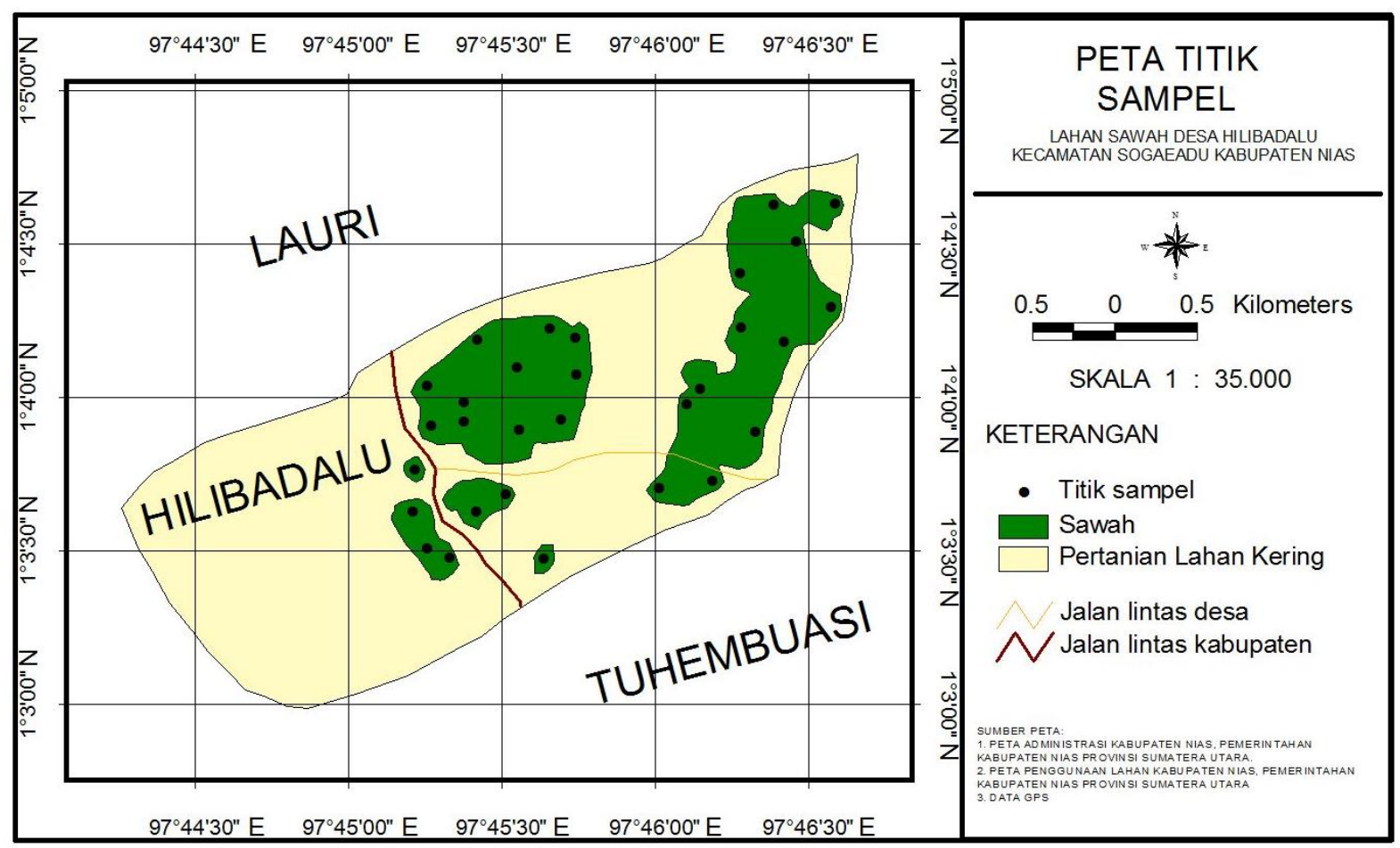

Gambar 1. Peta Titik Pengambil Sampel Tanah Lahan Sawah di Desa Hilibadalu

\section{HASIL DAN PEMBAHASAN}

\section{Kondisi Wilayah}

Desa Hilibadalu termasuk salah satu desa yang terdapat di Kecamatan Sogaeadu Kabupaten Nias memiliki luas wilayah sebesar 14,88 $\mathrm{km}^{2}$ atau setara dengan 1.488 ha. Wilayah ini berada pada ketinggian \pm 18 $\mathrm{m}$ di atas permukaan laut $(d p l)$ dan memiliki curah hujan sekitar 3000 - $3500 \mathrm{~mm} /$ tahun. Desa Hilibadalu memiliki luas lahan sawah seluas 190 ha dimana sawah yang terdapat di desa ini tergolong sawah tadah hujan. Jenis tanah yang terdapat di desa ini adalah tanah Ultisol.

\section{Pengelolaan Lahan}

Dari hasil kuisioner yang diberikan kepada petani diperoleh data pengelolaan lahan (pemupukan fosfor dan bahan organik). Berdasarkan data yang diperoleh diketahui bahwa sebagian besar petani tidak melakukan pemupukan fosfor di lahan sawah yaitu sebesar 93,33 \%, sedangkan yang melakukan pemupukan fosfor sebesar $6,67 \%$. Petani yang mengumpulkan/membakar jerami sisa panen sebesar 63,33 \% sedangkan yang membiarkan jerami sisa panen di lahan hanya sebesar 36,67 \%. Data pengelolaan lahan (pemupukan fosfor dan bahan organik) di daerah penelitian disajikan pada Tabel 1 berikut:

Tabel 3. Data Pengelolaan Lahan Oleh Petani

\begin{tabular}{clcc}
\hline \multicolumn{2}{c}{ Pengelolaan Lahan } & Jumlah & \% \\
\hline Pemupukan Fosfor & Dilakukan pemupukan & 2 & 6,67 \\
& Tidak dilakukan pemupukan & 28 & 93,33 \\
\hline & Total & $\mathbf{3 0}$ & $\mathbf{1 0 0}$ \\
\hline Pengelolaan Bahan & Dibiarkan & 11 & 36,67 \\
Organik & Dikumpulkan/dibakar & 19 & 63,33 \\
& Total & $\mathbf{3 0}$ & $\mathbf{1 0 0}$ \\
\hline
\end{tabular}




\section{Hasil analisis $\mathbf{P}$ Total, $\mathbf{P}$ Tersedia, $\mathbf{p H}$ Tanah dan C Organik. \\ P Total}

Dari hasil analisis $\mathrm{P}$ total contoh tanah dan evaluasi sifat kimia tanah menurut Staf Pusat Penelitian Tanah (1983) dan BPP Medan (1982) yang dapat dilihat pada Lampiran 1, diperoleh peta status hara $\mathrm{P}$ total (Gambar 2) dengan status sedang, tinggi dan sangat tinggi. $\mathrm{P}$ total pada sawah dengan kriteria sedang memiliki luasan terbesar dibandingkan dengan kriteria lain yaitu sebesar 81,59 ha $(42,94 \%)$, kriteria tinggi yaitu 81,15 ha $(42,71 \%)$, sedangkan kriteria sangat tinggi memiliki luasan yang lebih kecil dibandingkan kriteria lain yaitu sebesar 27,26 ha $(14,35 \%)$.

Status unsur hara $\mathrm{P}$ total pada daerah didominasi oleh kriteria sedang dikarenakan pengolahan lahan yang dilakukan oleh petani terutama mengenai pemasukan fosfor yang tidak dilakukan oleh sebagian besar petani (Tabel 3). Pemupukan dengan sumber unsur hara fosfor dapat meningkatkan kandungan $\mathrm{P}$ total dalam tanah dan status fosfor dengan kriteria sedang pada tanah sawah setidaknya harus dilakukan pemupukan SP 36 sebagai sumber fosfor dengan dosis rekomendasi 75 $\mathrm{kg} / \mathrm{ha}$. Hal ini sesuai dengan Deptan (2007) yang menyatakan bahwa rekomendasi pemupukan $\mathrm{P}$ pada tanaman padi sawah dengan kelas status hara $\mathrm{P}$ sedang adalah sebanyak $75 \mathrm{~kg} / \mathrm{ha}$ SP 36.

Status hara $\mathrm{P}$ total sedang pada lahan sawah di Desa Hilibadalu Kecamatan Sogaeadu Kabupaten Nias juga kemungkinan dapat disebabkan oleh adanya pembakaran jerami yang dilakukan oleh sebagian besar petani di lahan sawah. Karena pembakaran jerami dapat mengakibatkan unsur $\mathrm{P}$ dalam jerami hilang hingga 39-59 \% dimana seharunya unsur $\mathrm{P}$ tersebut dikembalikan ke tanah. Hal ini sesuai dengan literatur Husnain (2010) yang menyatakan bahwa persentase kandungan unsur hara yang hilang saat pembakaran jerami adalah 33-35 \% untuk $\mathrm{Si}$, 36-47 \% untuk K, 34-59 \% untuk P, 38-44 \% untuk Cam 42-48 \% untuk Mg dan 55-61\% untuk $\mathrm{Na}$. Luas wilayah untuk status hara $\mathrm{P}$ total disajikan pada tabel 4 .

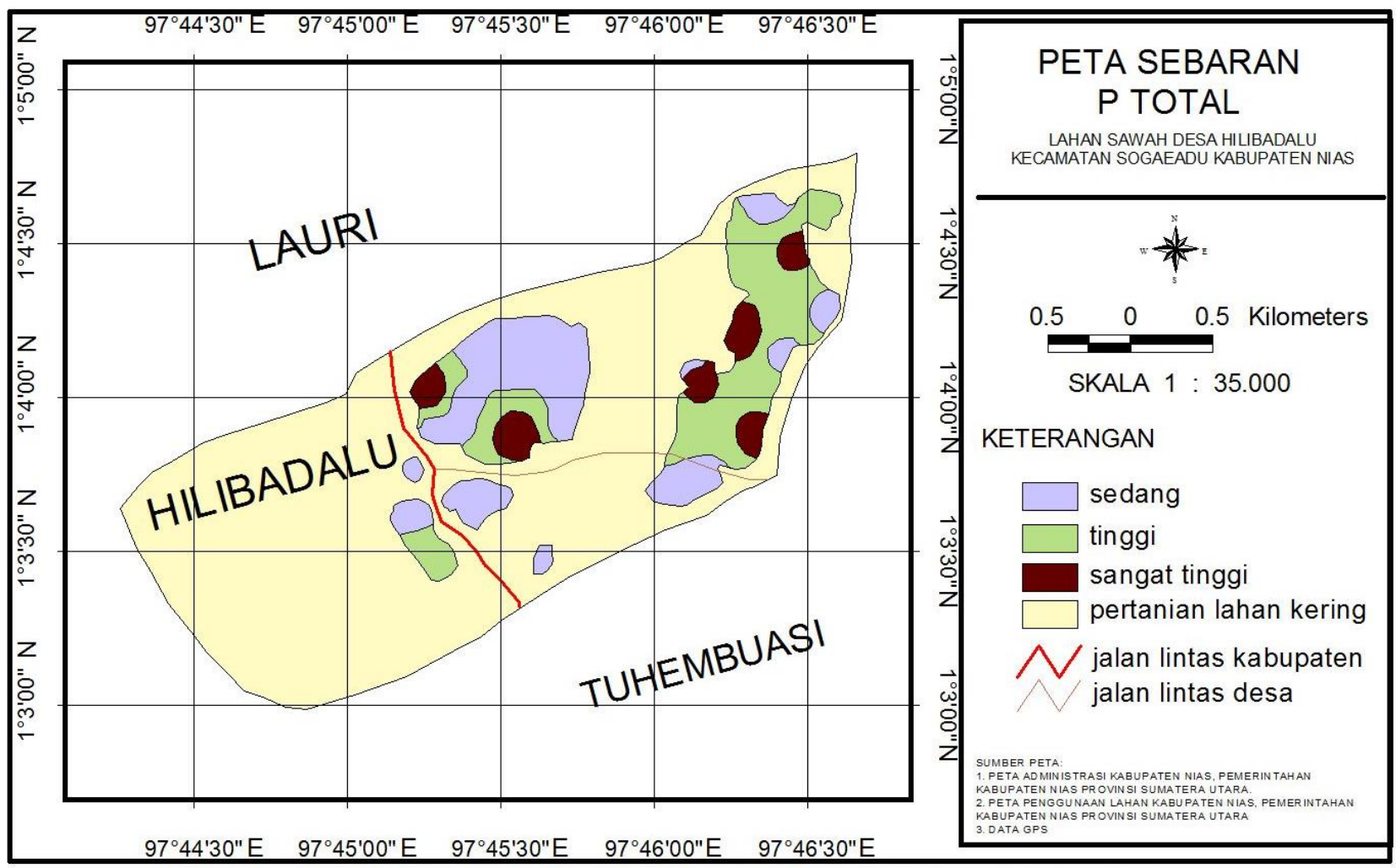


Gambar 2. Peta Sebaran P Total Lahan Sawah di Desa Hilibadalu Kecamatan Sogaeadu Kabupaten Nias

Tabel 4. Luas Wilayah Sebaran P Total Berdasarkan Kriteria

\begin{tabular}{ccc}
\hline Kriteria & Luas (ha) & Luas (\%) \\
\hline Sedang & 81,59 & 42,94 \\
Tinggi & 81,15 & 42,71 \\
Sangat Tinggi & 27,26 & 14,35 \\
\hline Total & $\mathbf{1 9 0}$ & $\mathbf{1 0 0}$
\end{tabular}

\section{P Tersedia}

Dari hasil analisis $\mathrm{P}$ tersedia contoh tanah dan evaluasi sifat kimia tanah menurut Staf Pusat Penelitian Tanah (1983) dan BPP Medan (1982) yang dapat dilihat pada Lampiran 1, diperoleh peta status hara $\mathrm{P}$ tersedia (Gambar 3) dengan status sangat rendah, rendah dan sedang. $\mathrm{P}$ tersedia pada lahan sawah dengan kriteria rendah memiliki luasan terbesar dibandingkan dengan kriteria yang lain yaitu sebesar 137,40 ha $(72,32 \%)$, kriteria sangat rendah memiliki luas sebesar 39,11 ha $(20,58 \%)$ dan kriteria sedang memiliki luasan lebih kecil yakni sebesar 13,49 ha $(7,10 \%)$.
Status unsur hara $\mathrm{P}$ tersedia pada daerah penelitian didominasi oleh kriteria rendah yaitu seluas 137,40 ha $(72,32 \%)$. Hal ini dapat disebabkan karena kandungan Al yang tinggi pada tanah Ultisol dapat mengikat unsur P menjadi tidak tersedia bagi tanaman. Seperti diketahui bahwa jenis tanah pada lahan sawah di Desa Hilibadalu adalah tanah Ultisol. Hal ini sesuai dengan literatur Prasetyo dan Suriadikarta (2006) yang menyatakan bahwa tanah Ultisol miskin kandungan unsur hara $\mathrm{P}$ dan kation-kation dapat ditukar seperti $\mathrm{Ca}, \mathrm{Mg}, \mathrm{Na}$ dan $\mathrm{K}$, serta kadar Al tinggi. Luas wilayah untuk status hara $\mathrm{P}$ total disajikan pada tabel 5. 


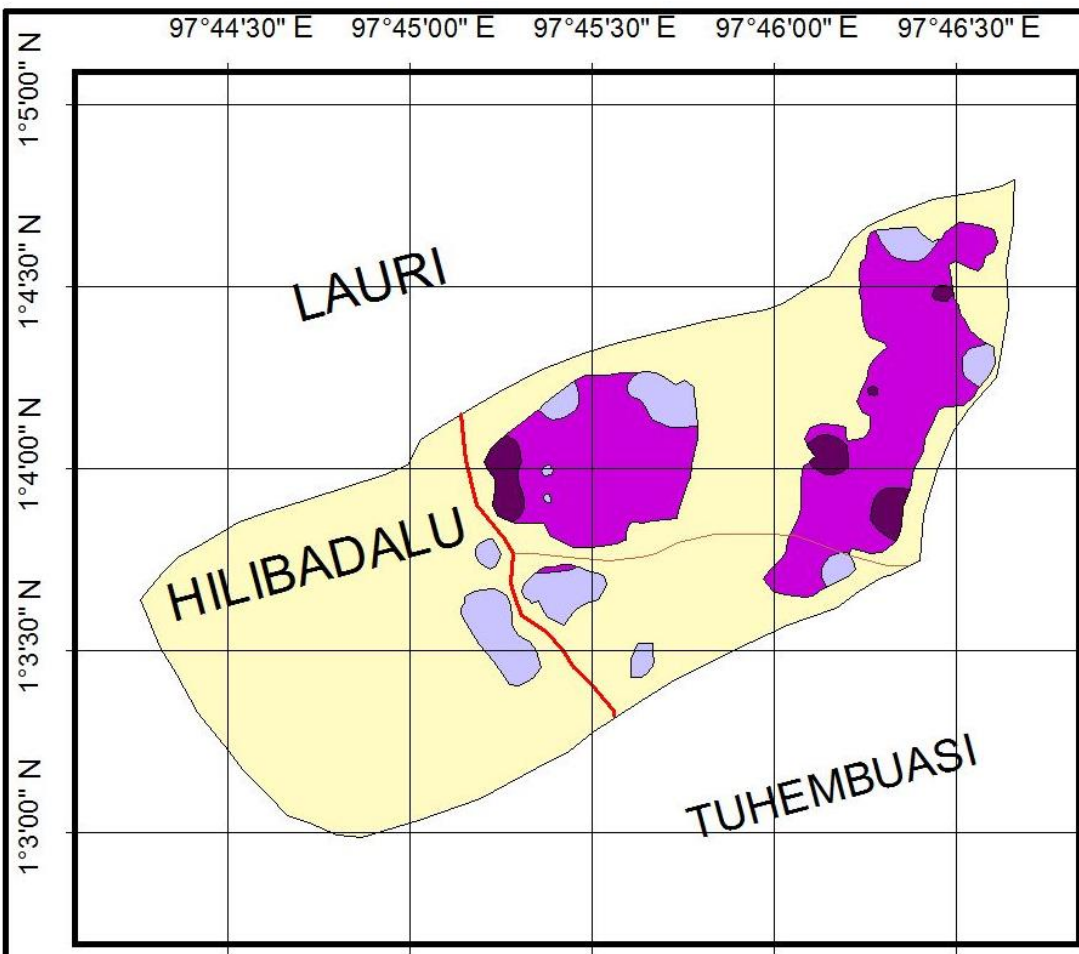

$97^{\circ} 44^{\prime} 30^{\prime \prime} \mathrm{E} \quad 97^{\circ} 45^{\prime} 00^{\prime \prime} \mathrm{E} \quad 97^{\circ} 45^{\prime} 30^{\prime \prime} \mathrm{E} \quad 97^{\circ} 46^{\prime} 00^{\prime \prime} \mathrm{E} \quad 97^{\circ} 46^{\prime} 30^{\prime \prime} \mathrm{E}$

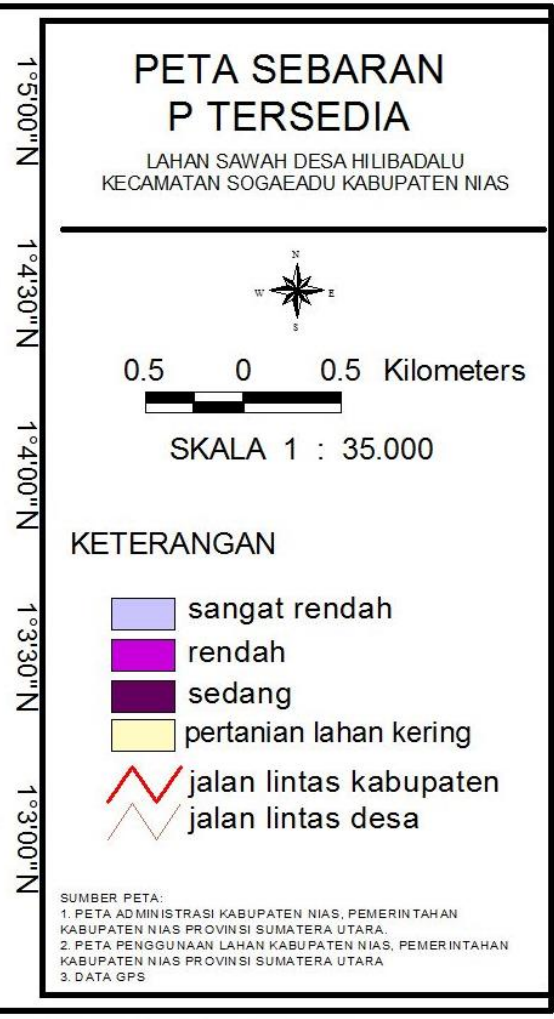

Gambar 3. Peta Sebaran P Tersedia Lahan Sawah di Desa Hilibadalu Kecamatan Sogaeadu Kabupaten 
Tabel 5. Luas Wilayah Sebaran P Tersedia Berdasarkan Kriteria

\begin{tabular}{ccc}
\hline Kriteria & Luas (ha) & Luas (\%) \\
\hline Sangat rendah & 39,11 & 20,58 \\
Rendah & 137,40 & 72,32 \\
Sedang & 13,49 & 7,10 \\
\hline Total & $\mathbf{1 9 0}$ & $\mathbf{1 0 0}$ \\
\hline
\end{tabular}

\section{pH Tanah}

Dari hasil analisis $\mathrm{pH}$ tanah contoh tanah dan evaluasi sifat kimia tanah menurut Staf Pusat Penelitian Tanah (1983) dan BPP Medan (1982) yang dapat dilihat pada Lampiran 1, diperoleh peta status $\mathrm{pH}$ tanah (Gambar 4) dengan status agak masam dan masam. $\mathrm{pH}$ tanah pada lahan sawah dengan kriteria masam lebih mendominasi yaitu sebesar 159,84 ha $(84,12 \%)$ sedangkan kriteria agak masam memiliki luas sebesar 30,16 ha $(15,88 \%)$.

Status $\mathrm{pH}$ tanah pada wilayah penelitian didominasi oleh kriteria masam yaitu seluas
159,84 ha $(84,12 \%)$. Hal ini dapat disebabkan karena jenis tanah yang terdapat pada wilayah penelitian adalah tanah Ultisol. Tanah Ultisol pada umumnya memiliki kekurangan salah satunya adalah tingkat kemasaman tanah yang tinggi. Hal ini sesuai dengan literatur Prasetyo dan Suriadikarta (2006) yang menyatakan bahwa tanah Ultisol memiliki reaksi tanah yang masam hingga sangat masam ( $\mathrm{pH}$ 5-3,10), mempunyai potensi keracunan $\mathrm{Al}$ yang tinggi dan miskin kandungan bahan organik. Luas wilayah untuk status $\mathrm{pH}$ tanah disajikan pada Tabel 6.

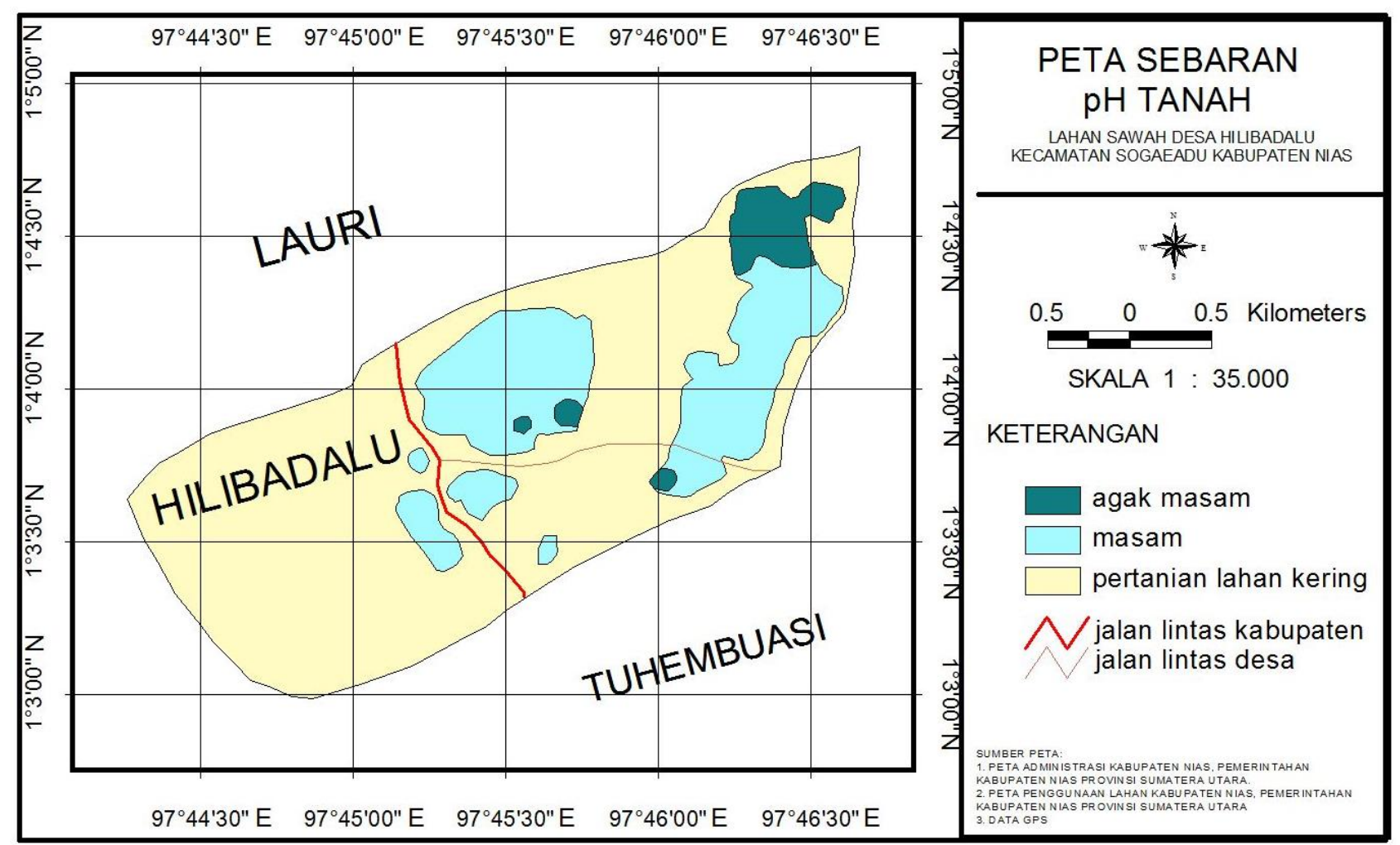

Gambar 4. Peta Sebaran pH Tanah Lahan Sawah di Desa Hilibadalu Kecamatan Sogaeadu Kabupaten Nias 
Tabel 6. Luas Wilayah Sebaran pH Tanah Berdasarkan Kriteria

\begin{tabular}{ccc}
\hline Kriteria & Luas (ha) & Luas (\%) \\
\hline Agak Masam & 30,16 & 15,88 \\
Masam & 159,84 & 84,12 \\
\hline Total & $\mathbf{1 9 0}$ & $\mathbf{1 0 0}$ \\
\hline
\end{tabular}

\section{C organik}

Dari hasil analisis $\mathrm{C}$ organik contoh tanah dan evaluasi sifat kimia tanah menurut Staf Pusat Penelitian Tanah (1983) dan BPP Medan (1982) yang dapat dilihat pada Lampiran 1, diperoleh peta status $\mathrm{C}$ organik (Gambar 5) dengan status sangat rendah, rendah dan sedang. $\mathrm{C}$ organik pada lahan sawah dengan kriteria rendah memiliki luasan yang lebih besar dibandingkan dengan kriteria lain yaitu sebesar 135,84 ha $(71,49 \%)$, kriteria sedang sebesar 51,10 ha $(26,89 \%)$ dan kriteria sangat rendah memiliki luas lebih rendah yakni sebesar 3,06 ha (1,62\%).

Status C organik pada wilayah penelitian didominasi oleh kriteria rendah dengan luas 135,84 ha $(71,49 \%)$. Hal ini disebabkan karena kebiasaan petani yang selalu mengumpulkan/membakar jerami padi setelah panen dan tidak mengembalikannya lagi ke lahan sawah. Petani yang melakukan pengumpulan/pembakaran pada jerami sisa panen adalah sebesar 63,33\% sedangkan yang mengembalikan (dibiarkan) jerami ke sawah sebanyak 36,67\% (Tabel 3). Hal ini didukung oleh penelitian Sumarno et al (2009) yang menyatakan bahwa jerami padi yang sebenarnya dapat dipergunakan untuk menambah kandungan bahan organik tanah, yang oleh petani lebih sering dibakar setelah panen, hal tersebut berakibat pada penurunan kandungan bahan organik tanah sawah. Sumarno et al manambahkan perilaku tersebut terjadi karena kesadaran dan pemahaman petani akan pentingnya peran bahan organik dalam tanah sawah masih rendah. Luas wilayah untuk status $\mathrm{C}$ organik disajikan pada Tabel 7. 


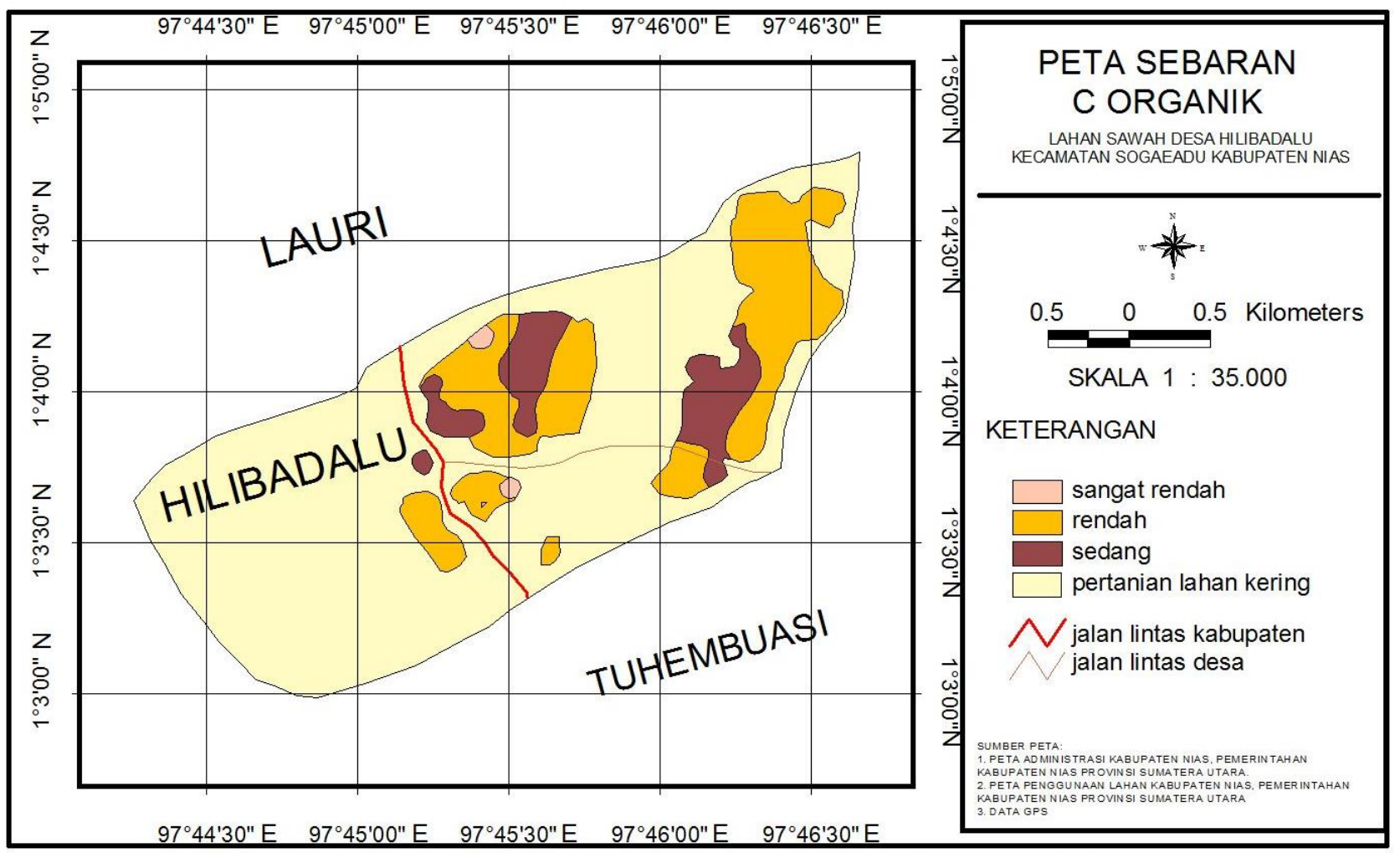

Gambar 5. Peta Sebaran C Organik Lahan Sawah di Desa Hilibadalu Kecamatan Sogaeadu Kabupaten Nias

Tabel 7. Luas Wilayah Sebaran C organik Berdasarkan Kriteria

\begin{tabular}{ccc}
\hline Kriteria & Luas (ha) & Luas (\%) \\
\hline Sangat Rendah & 3,06 & 1,62 \\
Rendah & 135,84 & 71,49 \\
Sedang & 51,10 & 26,89 \\
\hline Total & $\mathbf{1 9 0}$ & $\mathbf{1 0 0}$ \\
\hline
\end{tabular}

Analisis Hubungan P Total, P Tersedia dan C organik Terhadap Produksi Padi di Lahan Sawah Desa Hilibadalu Kecamatan Sogaeadu Kabupaten Nias

Nilai korelasi $\mathrm{P}$ total terhadap produksi adalah 0,146 dan bernilai positif. Meskipun demikian namun karena nilai signifikansinya 0,443 > 0,05 maka dapat disimpulkan bahwa tidak ada hubungan antara $\mathrm{P}$ total dengan produksi padi. Kemudian diperoleh persamaan regresi linear sederhana antara $\mathrm{P}$ total dan produksi padi adalah $\mathrm{y}=3,5193+4,0518 \mathrm{x}$ (Gambar 6). Namun karena $t$ hitung yang diperoleh < dari t tabel $(0,779<2,048)$ dan signifikansi $>0,05(0,443>0,05)$ maka diperoleh bahwa $\mathrm{P}$ total tidak berpengaruh terhadap produksi.

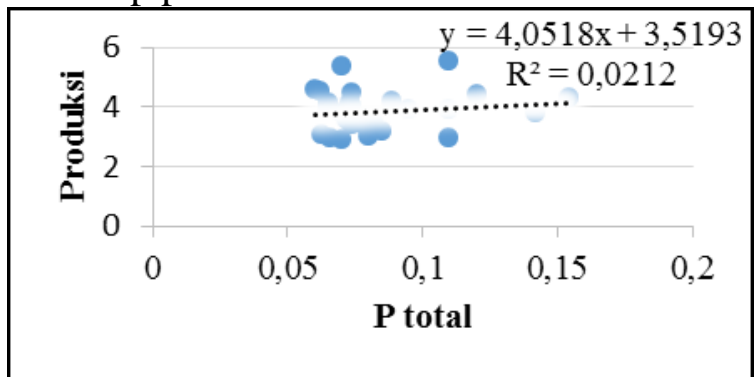

Gambar 6. Hubungan Antara P Total dan Produksi

Korelasi antara $\mathrm{P}$ tersedia dengan produksi memiliki nilai koefisien sebesar 0,529 pada tingkat signifikansi 0,01 . Dengan nilai koefisien tersebut dapat dikatakan bahwa 
tingkat keeratan hubungannya adalah pada tingkat sedang. Kemudian diperoleh persamaan regresi linear sederhana antara $P$ tersedia dan produksi padi adalah $\mathrm{y}=3,1889+$ 0,066x (Gambar 7). Nilai $t$ hitung yang diperoleh $>\mathrm{t}$ tabel $(3,302>2,048)$ dan signifikansi $<0,05(0,003<0,05)$ maka diperoleh bahwa $\mathrm{P}$ tersedia mempengaruhi produksi. Hal ini didukung oleh literatur Abdulrachman et al (2009) yang menyatakan bawah dalam pertumbuhannya padi memerlukan fosfor (P) dalam jumlah yang banyak untuk kegiatan pertumbuhan dan menghasilkan gabah yang tinggi. Nilai koefisien determinasi $\left(\mathrm{R}^{2}\right)$ sebesar 0,2803 yang berarti bahwa $\mathrm{P}$ tersedia memiliki pengaruh sebesar $28,03 \%$ terhadap produksi sedangkan $71,97 \%$ dipengaruhi oleh faktor-faktor lain selain $\mathrm{P}$ tersedia.

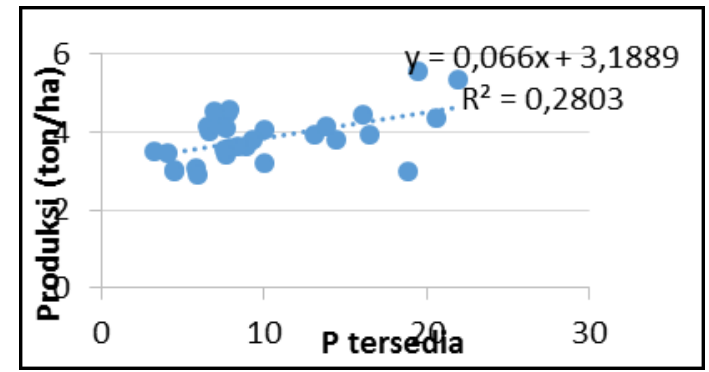

Gambar 7. Hubungan antara P Tersedia dengan Produksi

Korelasi antara $\mathrm{C}$ organik dengan produksi memiliki nilai koefisien sebesar 0,438 pada tingkat signifikansi 0,05 . Dengan nilai koefisien tersebut dapat dikatakan bahwa tingkat keeratan hubungannya ada pada tingkat sedang. Kemudian diperoleh persamaan regresi linear sederhana antara $\mathrm{C}$ organik dengan produksi padi adalah $\mathrm{y}=2,926+0,5168 \mathrm{x}$. Nilai $\mathrm{t}$ hitung yang diperoleh $>\mathrm{t}$ tabel $(2,577>2,048)$ dan signifikansi $<0,05(0,016<0,05)$, maka diperoleh bahwa $\mathrm{P}$ tersedia mempengaruhi produksi. Hal ini sesuai dengan literatur Setyorini et al (2010) yang menyatakan bahwa terdapat korelasi positif antara kadar bahan organik dan produktivitas tanaman padi sawah, dimana makin rendah kadar bahan organik makin rendah produktivitasnya. Nilai koefisien determinasi $\left(\mathrm{R}^{2}\right)$ sebesar 0,1917 yang berarti bahwa $\mathrm{C}$ organik memiliki pengaruh sebesar $19,17 \%$ terhadap produksi padi.

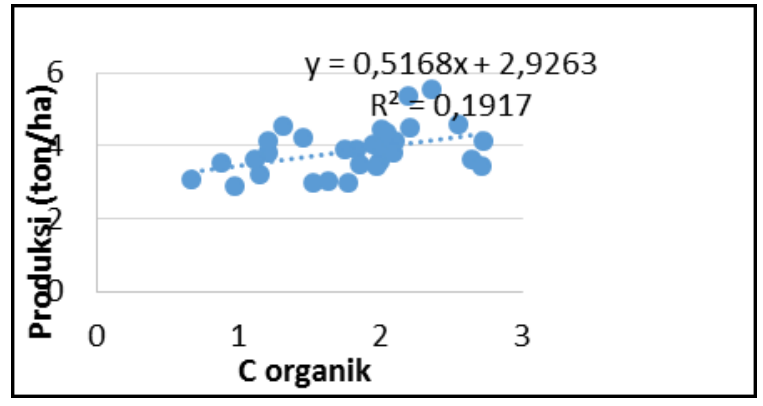

Gambar 8. Hubungan antara C Organik dan Produksi

\section{SIMPULAN}

P total digolongkan dalam 3 status hara, yakni sedang (81,59 ha), tinggi (81,15 ha) dan sangat tinggi $(27,26$ ha). $P$ tersedia digolongkan dalam 3 status hara, yakni sangat rendah (39,11 ha), rendah (137,40 ha) dan sedang (13,49 ha). pH tanah digolongkan dalam 2 status, yakni agak masam $(30,16$ ha) dan masam (159,84 ha). $\mathrm{C}$ organik digolongkan dalam 3 status hara, yakni sangat rendah (3,06 ha), rendah (135,84 ha) dan sedang $(51,10$ ha). $\mathrm{P}$ tersedia dan $\mathrm{C}$ organik mempengaruhi produksi padi di lahan sawah Desa Hilibadalu Kecamatan Gido Kabupaten Nias.

\section{DAFTAR PUSTAKA}

Abdulrachman, S. H. Sembiring dan Suyanto. 2009. Pemupukan Tanaman Padi. Balai Besar Penelitian Tanaman Padi. Pusat Penelitian dan Pengembangan Tanaman Pangan. Iptek Pangan No. 5, Hal: 123-166.

BPS. 2016. Kecamatan Sogaeadu Dalam Angka. Badan Pusat Statistik. Kabupaten Nias.

Deptan. 2007. Acuan Penetapan Rekomendasi Pupuk N, P dan K Pada Lahan Sawah Spesifik Lokasi. Sebagai Lampiran dari Permentan Nomor 40/Permentan/ OT.140/ 04/2007.

Hardjowigeno, S., H. Subagyo dan M. L. Rayes. 2004. Morfologi dan Klasifikasi Tanah Sawah. Dalam: Tanah Sawah dan Teknik Pengelolaannya. (ed). Agus. F., A. Adimihardja, S. 
Hardjowigeno. A. M. Fagi, dan W.

Hartatik Pusat Penelitian Dan

Pengembangan Tanah danAgroklimat.

Badan Penelitian dan Pengembangan

Pertanian, Bogor.Hal :1-28

Husnain. 2010. Kehilangan Unsur Hara Akibat

Pembakaran Jerami Padi dan Potensi

Pencemaran Lingkungan. Balai

Penelitian Tanah. Makalah diterbitkan

pada Prosiding Seminar Nasional

Sumberdaya Lahan Peranian. Bogor, 30 November - 1 Desember 2010.

Prasetyo, B. H. dan D. A. Suriadikarta. 2006.

Karakteristik, Potensi dan Pengelolaan

Tanah Ultisol Untuk Pengembangan

Pertanian Lahan Kering di Indonesia.

Balai Besar Penelitian dan

Pengembangan Sumberdaya Lahan

Pertanian, Balai Penelitian Tanah.

Jurnal Litbang Pertanian, 25 (2), 2006.

Rayes, M. L. 2007. Metode Inventarisasi

Sumber Daya Lahan. Penerbit Andi,

Yogyakarta.

Setyorini, D., S. Rachayati dan I. Las. 2010.

Pertanian Pada Ekosistem Lahan

Sawah. Dalam: Membalik

Kecenderungan Degradasi Sumberdaya Lahan dan Air. (ed.) Suradisastra, K.,

S. M. Pasaribu, B. Sayaka, A.

Dariah, Irsal Las, Haryono dan E.

Pasandaran. Balai Besar Litbang

Sumberdaya Lahan Pertanian, Jakarta.

Hal: 27-45

Sumarno, U. G. Kartasasmita dan D. Pasaribu. 2009. Pengayaan Kandungan Bahan

Organik Tanah Mendukung Keberlanjutan Sistem Produksi Padi Sawah. Peneliti Pusat Penelitian dan Pengembangan Tanaman Pangan. Iptek Tanaman Pangan Vol. 4 No. 1 - 2009 
Lampiran 1. Hasil analisis P Total, P Tersedia, $\mathrm{pH}$ dan $\mathrm{C}$ organik tanah sawah.

\begin{tabular}{|c|c|c|c|c|c|c|c|c|}
\hline $\begin{array}{l}\text { No } \\
\text { sampel }\end{array}$ & P Total & *Kriteria & $\begin{array}{l}\mathrm{P} \\
\text { Tersedia }\end{array}$ & *Kriteria & $\mathrm{pH}$ & *Kriteria & $\begin{array}{l}\mathrm{C} \\
\text { Organik }\end{array}$ & *Kriteria \\
\hline 1 & 0,110 & Sangat Tinggi & 16,500 & Sedang & 5,70 & Agak masam & 1,84 & Rendah \\
\hline 2 & 0,085 & Tinggi & 10,090 & Rendah & 5,60 & Agak masam & 1,16 & Rendah \\
\hline 3 & 0,066 & Sedang & 4,554 & Sangat rendah & 5,68 & Agak masam & 1,53 & Rendah \\
\hline 4 & 0,095 & Tinggi & 13,090 & Rendah & 5,57 & Masam & 1,75 & Rendah \\
\hline 5 & 0,074 & Sedang & 6,687 & Sangat rendah & 5,21 & Masam & 1,95 & Rendah \\
\hline 6 & 0,072 & Sedang & 7,920 & Sangat rendah & 5,20 & Masam & 2,00 & Rendah \\
\hline 7 & 0,120 & Sangat tinggi & 16,066 & Sedang & 5,39 & Masam & 2,01 & Sedang \\
\hline 8 & 0,110 & Sangat tinggi & 18,890 & Sedang & 5,33 & Masam & 1,78 & Rendah \\
\hline 9 & 0,065 & Sedang & 6,543 & Sangat rendah & 4,90 & Masam & 2,11 & Sedang \\
\hline 10 & 0,078 & Sedang & 8,920 & Sangat rendah & 5,12 & Masam & 2,65 & Sedang \\
\hline 11 & 0,065 & Sedang & 10,090 & Rendah & 5,67 & Agak masam & 2,02 & Sedang \\
\hline 12 & 0,142 & Sangat tinggi & 14,500 & Rendah & 5,60 & Agak masam & 2,10 & Sedang \\
\hline 13 & 0,074 & Sedang & 7,760 & Sangat rendah & 5,22 & Masam & 2,21 & Sedang \\
\hline 14 & 0,070 & Sedang & 22,010 & Sedang & 5,50 & Masam & 2,20 & Sedang \\
\hline 15 & 0,154 & Sangat tinggi & 20,589 & Sedang & 5,42 & Masam & 2,05 & Sedang \\
\hline 16 & 0,073 & Sedang & 13,870 & Rendah & 5,11 & Masam & 2,73 & Sedang \\
\hline 17 & 0,060 & Sedang & 7,880 & Sangat rendah & 5,02 & Masam & 2,56 & Sedang \\
\hline 18 & 0,080 & Tinggi & 3,300 & Sangat rendah & 5,43 & Masam & 1,86 & Rendah \\
\hline 19 & 0,070 & Sedang & 9,328 & Sangat rendah & 4,98 & Masam & 1,21 & Rendah \\
\hline 20 & 0,074 & Sedang & 7,700 & Sangat rendah & 4,90 & Masam & 1,98 & Rendah \\
\hline 21 & 0,089 & Tinggi & 7,090 & Sangat rendah & 5,12 & Masam & 1,46 & Rendah \\
\hline 22 & 0,062 & Sedang & 6,990 & Sangat rendah & 5,34 & Masam & 1,32 & Rendah \\
\hline 23 & 0,078 & Sedang & 4,121 & Sangat rendah & 5,20 & Masam & 2,72 & Sedang \\
\hline 24 & 0,110 & Sangat tinggi & 19,540 & Sedang & 5,36 & Masam & 2,37 & Sedang \\
\hline 25 & 0,078 & Sedang & 8,420 & Rendah & 5,60 & Agak masam & 1,12 & Rendah \\
\hline 26 & 0,080 & Tinggi & 4,550 & Sangat rendah & 5,21 & Masam & 1,64 & Rendah \\
\hline 27 & 0,074 & Sedang & 7,600 & Sangat rendah & 4,80 & Masam & 0,88 & Sangat rendah \\
\hline 28 & 0,063 & Sedang & 5,840 & Sangat rendah & 4,85 & Masam & 0,67 & Sangat rendah \\
\hline 29 & 0,070 & Sedang & 5,900 & Sangat rendah & 5,10 & Masam & 0,98 & Sangat rendah \\
\hline 30 & 0,065 & Sedang & 7,666 & Sangat rendah & 4,70 & Masam & 1,22 & Rendah \\
\hline
\end{tabular}

Ket: * Kriteria berdasarkan Staf Pusat Penelitian Tanah (1983) dan BPP Medan (1982). 